\title{
The TaqI Gene Polymorphisms of VDR and the Circulating 1,25-Dihydroxyvitamin D Levels Confer the Risk for the Keloid Scarring in Chinese Cohorts
}

\author{
Dongmei Yu Yong Shang Sai Luo Lijun Hao
}

Plastic and Cosmetic Center, The First Affiliated Hospital of Harbin Medical University, 23 Youzheng Str. Nangang District, 150001, Harbin, P.R. China

\section{Key Words}

Vitamin D receptor $\bullet 25$-Hydroxyvitamin D levels $•$ Keloid scar $•$ Risk

\begin{abstract}
Aim: to investigate the association between vitamin $D$ receptor polymorphisms and circulating 1,25-Dihydroxyvitamin D (1,25(OH)2D) levels with keloid scar (KS) risk. Methods: A total of 261 patients with KS and 261 normal healthy individuals were enrolled. VDR gene polymorphisms were determined. Circulating 1,25(OH)2D levels were detected. Results: In this study, we investigated the role of four loci of VDR gene polymorphisms in determining the risk of KS in a Chinese cohort. We found that the TaqI C > T polymorphism was closely associated with the KS incidence. Carriers with CC genotype of TaqI had a higher chance of developing KS. Stratification analyses by sex showed that this trend exists only in female subjects but not in male subjects. Furthermore, the TaqI C>T polymorphism affects the circulating 25-Hydroxyvitamin D levels. The CC carriers had a significantly lower mean circulating 1,25(OH)2D level than TT carriers and CT carriers. KS subjects had significantly lower mean serum circulating 1,25(OH)2D level than controls. The receiver operating characteristic curve analysis revealed that the serum circulating 1,25(OH)2D level at the cut-off point of $16.1 \mathrm{ng} / \mathrm{ml}$ could discriminate KS subjects from controls. Conclusion: Collectively, these data provide evidence that the vitamin D/VDR pathway plays an important role in the development of KS. The TaqI gene polymorphisms of VDR and circulating 1,25(OH)2D levels may thus be used as potential markers for prediction of KS development.
\end{abstract}


Yu et al.: VDR Gene Polymorphisms, Circulating 1,25-Dihydroxyvitamin D and Keloid Scarring

\section{Introduction}

Keloid scar (KS) is a benign hyperproliferative growth of dermal fibroblasts characterized by the excessive deposition of extracellular matrix components. The incidence of KS has been estimated to be approximately $4-6 \%$ in the general population and up to $16 \%$ in people of African cohorts [1-3]. Research in the past decades attempted to identify genetic, cellular, and molecular factors responsible for the incidence and development of KS, yet the mechanism of KS formation is largely unknown [4, 5]. Increased familial aggregation, a higher prevalence in certain races, parallelism in identical twins, and alterations in gene expression favor the contribution of genetic risk factors to the development of KS [6]. Some genetic markers have been reported to have significant importance in diagnosis, prognosis, and development of KS.

Vitamin D and its metabolites play an important role in calcium homeostasis, bone remodeling, hormone secretion, cell proliferation and differentiation [7]. Recent studies also suggest a beneficial role of vitamin $D$ in slowing the progression of tissue fibrosis. A previous study in vivo revealed vitamin D supplements increase promoter activity of cultured keloid fibroblasts and decrease fibrosis, suggesting that vitamin D supplementation could be a preventive early treatment strategy for keloid and related fibrotic disorders [8].

The effect of vitamin D is mediated by vitamin D receptor (VDR), a member of the nuclear receptor super-family of ligand-inducible transcription factors involved in many pathological processes [9-11]. The expression of VDR in cultured keloid fibroblasts has been confirmed [8]; however, there is no study regarding the association between VDR level and KS in a clinical setting. In addition, whether the genetic variants of VDR are associated with the risk for KS has not been investigated In this study, we enrolled KS patients and healthy controls to testify this possible association.

\section{Materials and Methods}

\section{Subjects}

A total of 261 patients between the ages of 19-55 years old with KS were recruited from our hospital. Patients who had KS due to any syndrome, skin disorder, hypertrophic scars, or genetic or chromosomal disorders were excluded from the study. The controls comprised 261 normal healthy individuals who were devoid of any keloid. The study was approved by the ethics committees of our hospital and written informed consent was obtained from each participant.

\section{Sample Collection and Genotyping}

Venous blood (10 ml) was collected from each patient into tubes containing $50 \mathrm{mmol}$ of EDTA per liter, and genomic DNA was isolated with DNA blood kit, according to manufacturer's instructions. Four diallelic polymorphisms of the VDR were genotyped: FokI C $>$ T (rs10735810) and TaqI T>C (rs10735810) polymorphic sites on the coding sequence, BsmI A>G (rs1544410) and ApaI G>T (rs7975232) on the last intron. The polymerase chain reaction (PCR) technique was applied and followed by restriction fragment length polymorphism assays. The primer and conditions for VDR gene polymorphisms were listed in Table 1. All PCR products were sized by electrophoresis on a $2 \%$ agarose gel stained with ethidium bromide.

\section{Measurement of serum 1,25(OH)2D}

A radioimmunoassay kit from Immunodiagnostic system, Boldon, UK, was used to analyze the $1,25(\mathrm{OH}) 2 \mathrm{D}$ levels. This assay had a sensitivity of $100 \%$ for $1,25(\mathrm{OH}) 2 \mathrm{D} 3$ and $91 \%$ for $1,25(\mathrm{OH}) 2 \mathrm{D} 2$. Detection limit was $8 \mathrm{pmol} / \mathrm{L}$ for 1,25(OH)2D and the inter-assay variations were $13.6 \%$, 9.6\% and 9.6\% for concentrations of $20.5 \mathrm{pmol} / \mathrm{L}, 60.8 \mathrm{pmol} / \mathrm{L}$ and $135.2 \mathrm{pmol} / \mathrm{L}$, respectively [12].

Statistical Analyses

$\chi 2$ tests were used to compare genotype frequency and demographic distributions between cases and controls. Multiple logistic regression analyses were used to evaluate if each polymorphism was indepen- 
Yu et al.: VDR Gene Polymorphisms, Circulating 1,25-Dihydroxyvitamin D and Keloid Scarring

\begin{tabular}{|c|c|c|c|}
\hline $\begin{array}{c}\text { VDR gene } \\
\text { polymorphisms }\end{array}$ & Primer & Base change & $\begin{array}{c}\text { Annealing } \\
\text { temperature }\end{array}$ \\
\hline \multirow[t]{2}{*}{ FokI } & 5'AGCTGGCCCTGGCACTGACTCTGCTCT3'(F) & $\mathrm{C} / \mathrm{T}$ & $61^{\circ} \mathrm{C}$ \\
\hline & 5'ATGGAAACACCTTGCTTCTTCTCCCTC 3'(R) & & \\
\hline \multirow[t]{2}{*}{ BsmI } & 5'CAACCAAGACTACAAGTACCGCGTCAGTGA3'(F) & $\mathrm{G} / \mathrm{A}$ & $57^{\circ} \mathrm{C}$ \\
\hline & 5'AACCAGCGGGAAGAGGTCAAGGG3'(R) & & \\
\hline \multirow[t]{2}{*}{ ApaI } & 5'CAGAGCATGGACAGGGAGCAA3'(F) & $\mathrm{G} / \mathrm{T}$ & $60^{\circ} \mathrm{C}$ \\
\hline & 5'GCAACTCCTCATGGCTGAGGTCTC3'(R) & & \\
\hline \multirow[t]{2}{*}{ TaqI } & 5'CAGAGCATGGACAGGGAGCAA3'(F) & $\mathrm{T} / \mathrm{C}$ & $60^{\circ} \mathrm{C}$ \\
\hline & 5'GCAACTCCTCATGGCTGAGGTCTC3'(R) & & \\
\hline
\end{tabular}

Table 1. PCR-RFLP premiers and conditions for VDR gene polymorphisms

\begin{tabular}{lccc}
\hline Characteristic & KS=261 & Control=261 & $\mathrm{P}$ \\
\hline Sex (female, n) & 181 & 130 & $<0.001$ \\
Age(mean \pm SD) & $24.7 \pm 6.24$ & $24.6 \pm 8.18$ & 0.569 \\
Tobacco users (n) & 80 & 75 & 0.351 \\
Alcohol users (n) & 63 & 59 & 0.378 \\
Serum1,25(OH)2D(mean \pm SD, ng/ml) & $15.1 \pm 3.4$ & $20.4 \pm 5.7$ & $<0.001$ \\
\hline
\end{tabular}

Table 2. The clinical characteristics of all subjects. SD: stand deviation

dently associated with KS while adjusting for the potential confounding effects of important clinical variables. The odds ratios (OR) and 95\% confidence intervals (CIs) were calculated. The receiver operating characteristic curve (ROC) analyses was performed to determine whether serum circulating 1,25(OH)2D can discriminate KS subjects from controls. P $<0.05$ was considered statistically significant. All analyses were performed by using SPSS software (Statistical Package for the Social Sciences, version 16.0, SPSS Inc, Chicago, IL, USA).

\section{Results}

\section{Patient Characteristics}

The clinical characteristics of all subjects are showed in Table 2. There were no significant differences in mean age, tobacco and alcohol use $(\mathrm{P}>0.05)$. The KS group was found to include more females than the control group $(\mathrm{P}<0.001)$. In addition, KS subjects had significantly lower serum 1,25(OH)2D than controls $(\mathrm{P}<0.001)$.

Genotype frequencies of VDR polymorphisms between KS and controls were found to be in Hardy-Weinberg equilibrium (all $P>0.05$ ). The genotype and the allele frequencies of Fok I, Bsm and ApaI were not significantly different between the KS and controls (all $\mathrm{P}>0.05$ ). However, the genotypic and allelic frequencies of TaqI $\mathrm{T}>\mathrm{C}$ were significantly different between KS and controls. KS subjects had markedly higher CC genotype of TaqI than controls ( $29 \%$ vs. $16 \%$, overall $\mathrm{P}<0.001$, Table 3 ). With TT of as reference, multivariate logistic regression analysis showed the CC genotype carriers had a higher chance of having KS (adjusted $\mathrm{OR}=3.334,95 \% \mathrm{CI}: 2.042-5.276$, adjusted $\mathrm{P}<0.001$ ) after adjusting for age, sex, tobacco and alcohol use and serum 1,25(OH)2D. Being a carrier of the $C$ allele represented a higher risk for KS after adjustment with the above mentioned clinical variables (adjusted OR=1.658, adjusted $\mathrm{P}<0.001$ ) compared with $\mathrm{T}$ allele carriage. However, multivariate logistic regression analysis did not reveal any association between of Fok I, Bsm and ApaI polymorphisms and $\mathrm{KS}$ risk in these patients (all $\mathrm{P}>0.05$ ).

We next analyzed the association between KS risk and the circulating serum 1,25(OH)2D levels. For TaqI polymorphism, we found that the TaqI genetic variants distributions were 


\section{Cellular Physiology $\quad$ Cell Physiol Biochem 2013;32:39-45 and Biochemistry

\begin{tabular}{|c|c|c|c|c|c|c|c|c|c|}
\hline & & \multirow{2}{*}{$\begin{array}{c}\text { KS } \\
\mathrm{N}\end{array}$} & \multicolumn{3}{|c|}{ Control } & \multirow[t]{2}{*}{$\begin{array}{c}\text { adjusted } \\
\text { OR }\end{array}$} & \multicolumn{2}{|c|}{$95 \% \mathrm{CI}$} & \multirow[t]{2}{*}{$\begin{array}{c}\text { adjusted } \\
\text { P }\end{array}$} \\
\hline & & & $\%$ & $\mathrm{~N}$ & $\%$ & & & & \\
\hline \multirow[t]{5}{*}{ ApaI } & TT & 90 & $30 \%$ & 86 & $28 \%$ & 1.000 & & & \\
\hline & TG & 124 & $41 \%$ & 129 & $43 \%$ & 0.919 & 0.614 & 1.317 & 0.668 \\
\hline & GG & 47 & $16 \%$ & 46 & $15 \%$ & 0.976 & 0.552 & 1.637 & 0.926 \\
\hline & $\mathrm{T}$ & 304 & $51 \%$ & 301 & $50 \%$ & 1.000 & & & \\
\hline & $\mathrm{G}$ & 295 & $49 \%$ & 304 & $50 \%$ & 0.961 & 0.764 & 1.214 & 0.747 \\
\hline \multirow[t]{5}{*}{ BsmI } & $\mathrm{AA}$ & 62 & $23 \%$ & 63 & $23 \%$ & 1.000 & & & \\
\hline & $\mathrm{AG}$ & 113 & $41 \%$ & 116 & $42 \%$ & 0.990 & 0.640 & 1.531 & 0.963 \\
\hline & GG & 86 & $31 \%$ & 82 & $29 \%$ & 1.066 & 0.671 & 1.693 & 0.788 \\
\hline & A & 237 & $43 \%$ & 242 & $44 \%$ & 1.000 & & & \\
\hline & $\mathrm{G}$ & 312 & $57 \%$ & 314 & $56 \%$ & 1.015 & 0.800 & 1.287 & 0.905 \\
\hline \multirow[t]{5}{*}{ FokI } & TT & 68 & $24 \%$ & 57 & $20 \%$ & 1.000 & & & \\
\hline & CT & 120 & $42 \%$ & 125 & $44 \%$ & 0.805 & 0.522 & 1.240 & 0.324 \\
\hline & CC & 73 & $26 \%$ & 79 & $28 \%$ & 0.775 & 0.482 & 1.245 & 0.291 \\
\hline & $\mathrm{T}$ & 256 & $45 \%$ & 239 & $42 \%$ & 1.000 & & & \\
\hline & C & 313 & $55 \%$ & 329 & $58 \%$ & 0.888 & 0.702 & 1.123 & 0.322 \\
\hline \multirow[t]{5}{*}{ TaqI } & TT & 49 & $17 \%$ & 94 & $32 \%$ & 1.000 & & & \\
\hline & TC & 129 & $45 \%$ & 119 & $40 \%$ & 1.280 & 0.858 & 2.184 & 0.051 \\
\hline & CC & 83 & $29 \%$ & 48 & $16 \%$ & 3.334 & 2.042 & 5.276 & $<0.001$ \\
\hline & $\mathrm{T}$ & 227 & $40 \%$ & 307 & $52 \%$ & 1.000 & & & \\
\hline & $\mathrm{C}$ & 341 & $60 \%$ & 286 & $48 \%$ & 1.657 & 1.248 & 2.253 & $<0.001$ \\
\hline
\end{tabular}

Table 3. The genotype and the allele frequencies of VDR gene polymorphism between the KS and controls. OR and $P$ were adjusted by age, sex, tobacco and alcohol use and serum 1,25(OH)2D levels

\begin{tabular}{|c|c|c|c|c|c|c|c|c|c|}
\hline & \multirow[t]{2}{*}{ TaqI $\mathrm{T}>\mathrm{C}$} & \multicolumn{2}{|l|}{ KS } & \multicolumn{2}{|l|}{ Control } & \multirow[t]{2}{*}{$\begin{array}{c}\text { adjusted } \\
\text { OR }\end{array}$} & \multicolumn{2}{|c|}{$95 \% \mathrm{CI}$} & \multirow[t]{2}{*}{$\begin{array}{l}\text { adjusted } \\
\text { P value }\end{array}$} \\
\hline & & $\mathrm{N}=261$ & $\%$ & $\mathrm{~N}=261$ & $\%$ & & & & \\
\hline \multirow[t]{5}{*}{ Male } & TT & 18 & $26 \%$ & 21 & $29 \%$ & 1.000 & & & \\
\hline & TC & 27 & $39 \%$ & 31 & $43 \%$ & 1.065 & 0.443 & 2.523 & 0.958 \\
\hline & CC & 20 & $29 \%$ & 10 & $14 \%$ & 2.333 & 0.858 & 6.228 & 0.074 \\
\hline & $\mathrm{T}$ & 63 & $46 \%$ & 73 & $50 \%$ & 1.000 & & & \\
\hline & C & 74 & $54 \%$ & 72 & $50 \%$ & 1.191 & 0.746 & 1.937 & 0.472 \\
\hline \multirow[t]{4}{*}{ Female } & TT & 32 & $15 \%$ & 64 & $28 \%$ & 1.000 & & & \\
\hline & $\mathrm{TC}$ & 98 & $46 \%$ & 97 & $42 \%$ & 1.021 & 0.785 & 3.374 & 0.922 \\
\hline & CC & 66 & $31 \%$ & 38 & $17 \%$ & 3.474 & 1.940 & 6.220 & $<0.001$ \\
\hline & $\mathrm{T}$ & 162 & $38 \%$ & 225 & $49 \%$ & 1.000 & & & \\
\hline
\end{tabular}

Table 4. The genotype and the allele frequencies of TaqI gene polymorphism between the KS and controls stratified by sex. OR and P were adjusted by age, sex, tobacco and alcohol use and serum 1,25(OH)2D levels

only significant in the female groups but not in the male groups. Multivariate logistic regression analysis showed the CC genotype of TaqI to be associated with a significantly higher risk for KS in female subjects (adjusted OR=3.474, $\mathrm{P}<0.001$, compared with TT carriage) but not in male subjects $(\mathrm{P}=0.059$, compared with TT carriage, Table 4$)$. The KS risk associated with Fok I, Bsm and ApaI polymorphisms were similar between male and female groups (data not shown).

KS patients had a significantly lower mean serum 1,25(OH)2D level that controls. We next analyzed the influence of the VDR genetic polymorphism on the serum 1,25(OH)2D levels. When stratified by the individual genotypes, we found that the TaqI was the only polymoprhism that affected the serum $1,25(\mathrm{OH}) 2 \mathrm{D}$ levels. The CC carriers had a significantly lower serum 1,25(OH)2D level $(12.9 \pm 3.6 \mathrm{ng} / \mathrm{ml})$ compared with TT carriers $(17.4 \pm 3.4 \mathrm{ng} /$ $\mathrm{ml}, \mathrm{P}=0.011$ vs. CC) and CT carriers $(16.9 \pm 4.1 \mathrm{ng} / \mathrm{ml}, \mathrm{P}=0.007$, vs. CC, Fig. 1$)$. 


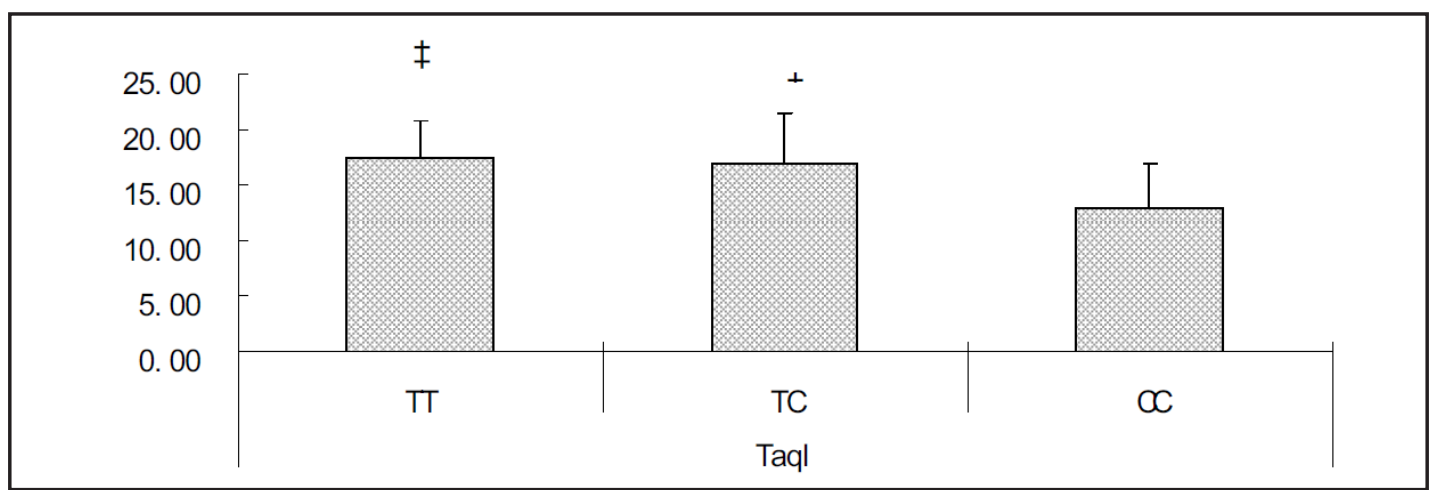

Fig. 1. The serum 1,25(OH)2D levels stratified by TaqI gene polymorphism. vs. CC $P=0.011 \neq$ vs. CC $P=0.007$.

Fig. 2. The ROC analyses of serum 1,25(OH)2D level in discrimination of $\mathrm{KS}$ from controls. AUC $=0.911, \mathrm{P}=0.018$

We further performed the ROC analyses to determine serum 1,25(OH)2D level as a biomarker to discriminate the KS subjects from controls. We found that the serum $1,25(\mathrm{OH}) 2 \mathrm{D}$ level at the cut-off point of 16.1 $\mathrm{ng} / \mathrm{ml}$ distinguished KS subjects from controls. (area under curve $=0.911, \mathrm{P}=0.018$, sensitivity $=87.2 \%$ and specificity $=78.3 \%$ ) (Fig.

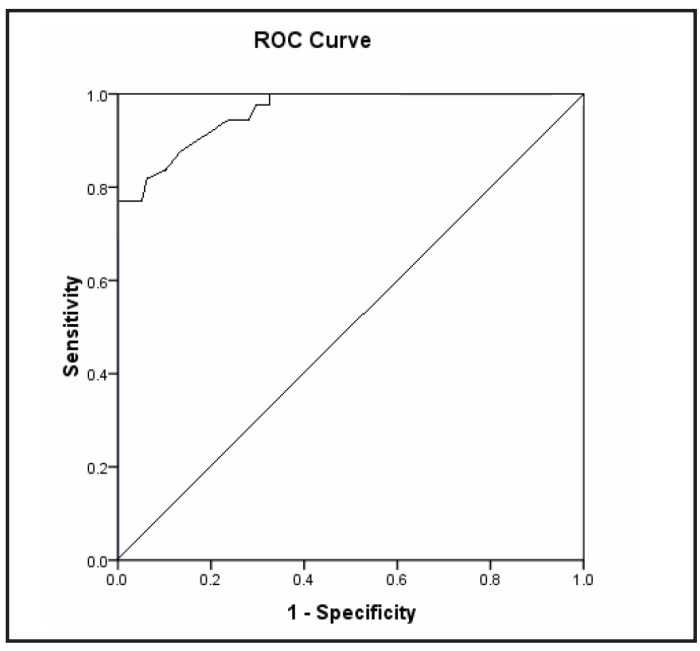
2).

\section{Discussion}

In this study, we investigated the role of four loci of VDR gene polymorphisms in determining the risk of KS in a Chinese cohort. We found that the TaqI C>T polymorphism was closely associated with KS incidence. Carriers with CC genotype of TaqI had a higher chance to develop KS. Stratification analyses by sex showed that this trend existed only in female subjects but not in male subjects. The TaqI $\mathrm{C}>\mathrm{T}$ polymorphism also affected the serum 1,25(OH)2D levels. The CC carriers had a significantly lower serum 1,25(OH)2D level compared with TT carriers and CT carriers. KS subjects had a significantly lower mean serum $1,25(\mathrm{OH}) 2 \mathrm{D}$ level than controls. ROC analyses revealed that the serum 1,25(OH)2D level at the cut-off point of $16.1 \mathrm{ng} / \mathrm{ml}$ could discriminate KS subjects from controls with an area under curve. Collectively, these data provide evidence that the Vit D/VDR plays an important role in the development of KS. Moreover, the TaqI gene polymorphisms of VDR and the circulating 1,25(OH)2D levels may be used as potential marker for prediction of KS incidence.

Vitamin D has been shown to have anti-proliferative effects in a wide variety of pathological conditions, such as cancers and fibroproliferative diseases. The anticancer effects of vitamin $\mathrm{D}$ are mediated primarily by its active metabolite, 1,25 -dihydroxyvitamin $\mathrm{D}$ (calcitriol), through vitamin D receptor (VDR) signaling [13]. Vitamin D has been shown to play an important role in collagen synthesis and degradation. In the rat glomerulonephritis model and heart fibrosis, Vitamin D was shown to inhibit collagen synthesis in interstitial fibrosis 
Yu et al.: VDR Gene Polymorphisms, Circulating 1,25-Dihydroxyvitamin D and Keloid Scarring

and the accumulation of interstitial matrix components by suppressing transforming growth factor (TGF)- $\beta 1$ gene expression or by up-regulating antifibrotic HGF gene expression [1416]. Clinical studies also provide evidence that the deficiency in vitamin $D$ and its active metabolites is closely associated with fibroproliferative diseases, and the administration of vitamin D is an effective treatment for skin fibrosis diseases such as scleroderma [17]. The imbalance between collagen synthesis and degradation plays an important role in the KS process, implicating the influence of vitamin D in the development of KS [18-20].

The vitamin D receptor (VDR), expressed in normal and malignant prostate cells, mediates the biological actions of 1,25(OH)2D [21]. VDR is located on the long arm of 12. chromosome (3q11 locus) and consists of 11 exons [22]. Several common polymorphisms in the VDR gene have been described [23]. The FokI polymorphism is a $\mathrm{T}>\mathrm{C}$ transition polymorphism (ATG to ACG) at the first of two potential translation initiation sites in exon II has been defined using the FokI restriction endonuclease. The TaqI polymorphism is a T/C nucleotide substitution (ATT to ATC) leading to a synonymous change at codon 352 (isoleucine) in exon IX. Bsm I and ApaI restriction site polymorphisms occur in the intron separating exons VIII and IX. When the genotypes were analyzed with respect to 25-OH-Vitamin D levels in an Indian population, a significant association was seen for the Taq I SNP but not with the Fok I [24]. In the present study, we observed the similar result that the TaqI, rather than the other three loci, affected the circulating 1,25(OH)2D.

Several limitations in this study need to be addressed. This study was a single-center cohort investigation on a relatively small scale, and thus, replication studies with large independent cohorts are warranted. Secondly, we did not detect the VDR expression in KS tissue. The detection of VDR protein will help to clarify the effect of the genetic variants of VDR gene on KS formation.

\section{Conflict of Interest}

None

\section{Acknowledgements}

We thank Dr. Xuwei Hou for his help in statical analysis. We thank Dr.Liu Jin for her help in the genotyping of OPN polymorphisms. We thanks Ms. Elisa Miguel for her help in language revisions.

\section{References}

-1 Lee JY, Yang CC, Chao SC, Wong TW: Histopathological differential diagnosis of keloid and hypertrophic scar. Am J Dermatopathol 2004;26:379-384.

-2 Emami A, Halim AS, Salahshourifar I, Yussof SJ, Khoo TL, Kannan TP: Association of TGFbeta1 and SMAD4 variants in the etiology of keloid scar in the Malay population. Arch Dermatol Res 2012;304:541-547.

3 Tsao SS, Dover JS, Arndt KA, Kaminer MS: Scar management: keloid, hypertrophic, atrophic, and acne scars. Semin Cutan Med Surg 2002;21:46-75.

-4 Ehrlich HP, Desmouliere A, Diegelmann RF, Cohen IK, Compton CC, Garner WL, Kapanci Y, Gabbiani G: Morphological and immunochemical differences between keloid and hypertrophic scar. Am J Pathol 1994;145:105-113.

5 Rossiello L, D'Andrea F, Grella R, Signoriello G, Abbondanza C, De Rosa C, Prudente M, Morlando M, Rossiello R: Differential expression of cyclooxygenases in hypertrophic scar and keloid tissues. Wound Repair Regen 2009;17:750-757. 
Yu et al.: VDR Gene Polymorphisms, Circulating 1,25-Dihydroxyvitamin D and Keloid Scarring

6 Halim AS, Emami A, Salahshourifar I, Kannan TP: Keloid scarring: understanding the genetic basis, advances, and prospects. Arch Plast Surg 2012;39:184-189.

7 Muller DN, Kleinewietfeld M, Kvakan H: Vitamin D review. J Renin Angiotensin Aldosterone Syst 2011;12:125-128.

8 Zhang GY, Cheng T, Luan Q Liao T, Nie CL, Zheng X, Xie XG, Gao WY: Vitamin D: a novel therapeutic approach for keloid, an in vitro analysis. Br J Dermatol 2011;164:729-737.

-9 Subramaniam N, Leong GM, Cock TA, Flanagan JL, Fong C, Eisman JA, Kouzmenko AP: Cross-talk between 1,25-dihydroxyvitamin D3 and transforming growth factor-beta signaling requires binding of VDR and Smad3 proteins to their cognate DNA recognition elements. J Biol Chem 2001;276:15741-15746.

10 Kato S, Yoko Y: [VDR function in skin]. Clin Calcium 2004;14:116-119.

11 Slattery ML: Vitamin D receptor gene (VDR) associations with cancer. Nutr Rev 2007;65:S102-104.

12 Christensen MH, Apalset EM, Nordbo Y, Varhaug JE, Mellgren G, Lien EA: 1,25-dihydroxyvitamin d and the vitamin $d$ receptor gene polymorphism apa1 influence bone mineral density in primary hyperparathyroidism. PLoS One 2013;8:e56019.

13 Srinivasan M, Parwani AV, Hershberger PA, Lenzner DE, Weissfeld JL: Nuclear vitamin D receptor expression is associated with improved survival in non-small cell lung cancer. J Steroid Biochem Mol Biol 2011;123:30-36.

14 Li Y, Spataro BC, Yang J, Dai C, Liu Y: 1,25-dihydroxyvitamin D inhibits renal interstitial myofibroblast activation by inducing hepatocyte growth factor expression. Kidney Int 2005;68:1500-1510.

15 Tan X, Li Y, Liu Y: Paricalcitol attenuates renal interstitial fibrosis in obstructive nephropathy. J Am Soc Nephrol 2006;17:3382-3393.

16 Koleganova N, Piecha G, Ritz E, Gross ML: Calcitriol ameliorates capillary deficit and fibrosis of the heart in subtotally nephrectomized rats. Nephrol Dial Transplant 2009;24:778-787.

$\checkmark 17$ Humbert PG, Dupond JL, Rochefort A, Vasselet R, Lucas A, Laurent R, Agache P: Localized scleroderma-response to 1,25-dihydroxyvitamin D3. Clin Exp Dermatol 1990;15:396-398.

18 Diao JS, Xia WS, Yi CG, Wang YM, Li B, Xia W, Liu B, Guo SZ, Sun XD: Trichostatin A inhibits collagen synthesis and induces apoptosis in keloid fibroblasts. Arch Dermatol Res 2011;303:573-580.

19 Gao Z, Wang Z, Shi Y, Lin Z, Jiang H, Hou T, Wang Q, Yuan X, Zhao Y, Wu H, Jin Y: Modulation of collagen synthesis in keloid fibroblasts by silencing Smad2 with siRNA. Plast Reconstr Surg 2006;118:1328-1337.

20 Wang Z, Gao Z, Shi Y, Sun Y, Lin Z, Jiang H, Hou T, Wang Q, Yuan X, Zhu X, Wu H, Jin Y: Inhibition of Smad3 expression decreases collagen synthesis in keloid disease fibroblasts. J Plast Reconstr Aesthet Surg 2007;60:1193-1199.

21 Kato S: The function of vitamin D receptor in vitamin D action. J Biochem 2000;127:717-722.

-22 Whitfield GK, Remus LS, Jurutka PW, Zitzer H, Oza AK, Dang HT, Haussler CA, Galligan MA, Thatcher ML, Encinas Dominguez C, Haussler MR: Functionally relevant polymorphisms in the human nuclear vitamin D receptor gene. Mol Cell Endocrinol 2001;177:145-159.

23 Thakkinstian A, D'Este C, Attia J: Haplotype analysis of VDR gene polymorphisms: a meta-analysis. Osteoporos Int 2004;15:729-734.

24 Bhanushali AA, Lajpal N, Kulkarni SS, Chavan SS, Bagadi SS, Das BR: Frequency of fokI and taqI polymorphism of vitamin D receptor gene in Indian population and its association with 25-hydroxyvitamin D levels. Indian J Hum Genet 2009;15:108-113. 